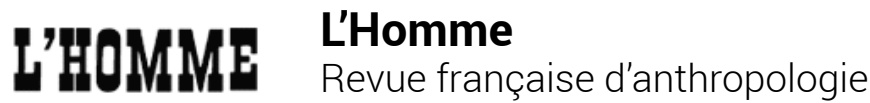

234-235 | 2020

Varia

\section{Jarrett Zigon, A War on People. Drug User Politics and a New Ethic of Community}

Erwan Autès

\section{(2) OpenEdition \\ 1 Journals}

Édition électronique

URL : https://journals.openedition.org/lhomme/37867

DOI : 10.4000//homme.37867

ISSN : 1953-8103

Éditeur

Éditions de l'EHESS

\section{Édition imprimée}

Date de publication : 14 octobre 2020

Pagination : 357-358

ISBN : 978-2-7132-2838-4

ISSN : 0439-4216

Référence électronique

Erwan Autès, "Jarrett Zigon, A War on People. Drug User Politics and a New Ethic of Community ", L'Homme [En ligne], 234-235 | 2020, mis en ligne le 14 octobre 2020, consulté le 04 janvier 2023. URL http://journals.openedition.org/lhomme/37867 ; DOI : https://doi.org/10.4000/lhomme.37867 

L

A RHÉTORIQUe de la guerre est une stratégie politique récurrente aux États-Unis, visant à renforcer le pouvoir exécutif face à une situation érigée en crise qui mettrait en danger la nation ${ }^{1}$. La guerre contre la drogue en est un exemple paradigmatique. La surveillance de masse, la criminalisation des déviances, la militarisation des forces de l'ordre, les thérapeutiques normalisant les individus sont autant de phénomènes entrelacés, conduisant l'anthropologue Jarrett Zigon au constat d'une guerre non seulement contre les consommateurs de drogues, mais aussi d'une guerre globale contre les gens (war on people). L'auteur défend l'idée d'une "ethnographie d'assemblage» (assemblic ethnography) et d'une anthropologie des potentialités, tissant des liens logiques entre des situations distantes. Il poursuit une recherche ambitieuse sur un phénomène global et complexe, sans en faire, pour reprendre Timothy Morton ${ }^{2}$, un «hyperobjet» (pp. 39-40) qui resterait insaisissable sur le terrain. La guerre contre la drogue s'exerce violemment à travers le monde, contre les producteurs comme contre les consommateurs (chap. I). Transformés par la rhétorique de la guerre en ennemis intérieurs, au motif de protéger le reste de la population, les drogués sont réduits à une figure déshumanisée, à une déchéance intériorisée par les consommateurs de drogues eux-mêmes, processus qui ne peut être rompu que par des actions militantes exposant, au contraire, leur humanité au grand jour (chap. II). Un mouvement international anti-guerre contre la drogue (anti-drug war movement) a ainsi ouvert des brèches, défriché des espaces de liberté. Une des victoires de ce mouvement est la reconnaissance, ici où là, dans des communautés ouvertes, de l'humanité des usagers de drogue. Ces derniers ont en commun d'avoir eu une expérience de la drogue soit directement soit par des proches et d'avoir été confrontés à la mort. Ils font potentiellement partie, à travers le monde, d'une vaste "communauté de ceux qui n'ont pas de communauté» ( $\mathrm{A}$ Community of Those without Community", chap. III). Envisager alors la liberté comme un désenclavement de la condition à laquelle la rhétorique de la guerre assigne les individus (disclosive freedom), autorise à (re) vivre, à se laisser aller de manière inventive (open letting-be) (chap. IV). Des usagers de drogues créent des espaces qui ouvrent la perspective d'autres "mondes», fondés sur l'écoute des singularités de chacun et sur l'attention portée aux autres (attuned care). Ces «mondes» sont préfigurés par des communautés ouvertes, parfois éphémères où, de passage, l'on pourrait être reçu par la question suivante: "Puis-je vous offrir quelque chose? Tranquillisants, aspirine, herbe, acides, coke?» (chap. V). Jarrett Zigon cite principalement trois lieux pour illustrer sa démonstration: l'association activiste Voices of Community and Leaders à New York (Vocal-Ny) ${ }^{3}$, l'association BrugerForeningen à Copenhague, où règne l'hospitalité, sauf à l'égard des cocaïnomanes (même les mondes les plus ouverts ont leurs frontières), et, enfin, le quartier de Downtown Eastside de Vancouver présenté comme un modèle alternatif inclusif à la guerre contre la drogue. Pour l'auteur, la salle d'injection sans danger (safe-injection) «Insite» est considérée comme le «noyau central d'où émane l'ordinaire de

1. Cf. Oren Gross \& Fionnuala Ni Aolain, «The Rhetoric of War: Words, Conflict, and Categorization Post-9/11 ", Cornell Journal of Law and Public Policy, 2014, 24 (2): 241-289.

2. Cf. Timothy Morton, Hyperobjects. Philosophy and Ecology After the End of the World. Minneapolis, University of Minnesota Press, 2013.

3. Dans le cas de New York, il est surprenant que la crise des opioïdes de 2013-2014 ne soit que brièvement évoquée, alors que le nombre de morts par overdose des opiö̈des avait dépassé celui des morts par accident de la route aux États-Unis. 
la réduction des risques dans ce nouveau monde» (p. 126).

Ce pari heuristique d'une perception foucaldo-orwellienne du monde social offre deux perspectives. La première restitue la cohérence d'un mouvement international anti-guerre contre la drogue, uni par des connexions intimes et des résonances comme l'expérience de la mort de proches (dyingwith), ou l'aspiration à "faire communauté». L'ensemble des témoignages du livre forme un chœur révélant la répression, la construction d'un monde imaginaire (fantasy world) rejetant les drogués aux confins de la société par des biopolitiques immunitaires. Jarrett Zigon forge le concept de «thérapeutique biopolitique" (biopolitical therapeutics), pour dénoncer des régimes de soins ayant pour but principal de normaliser les individus (normalizing care) (p. 121). Les moyens mis en œuvre fondés sur l'abstinence, par les nombreuses overdoses qu'ils provoquent à la sortie, suggèrent que "l'aspect biopolitique-thérapeutique est l'un des plus importants aspects mortellement dangereux de la guerre contre la drogue» (pp. 30-31). Les dispositifs de réduction des risques, en s'institutionnalisant, ont été dévoyés et sont devenus «une intervention thérapeutique financée par l'État, dirigée par des bureaucrates, des gestionnaires "formés à l'université" et des thérapeutes en santé publique, et donc largement hors des mains des usagers de drogues» (p. 47). Le propos ménage toutefois un rapport réflexif à la rhétorique de la biopolitique. Jarrett Zigon poursuit ses travaux sur les conceptions éthiques de l'humain. Les paradoxes de la production politique par la consommation de drogue à travers l'Occident restent toutefois implicites. Les nombreuses victoires locales du mouvement anti-guerre contre la drogue ne resituent pas l'ambivalence des politiques publiques, avec un curseur variant selon les pays, entre répression et intégration. Concentrée sur la rhétorique de la guerre contre la drogue, l'analyse délaisse le difficile équilibre des politiques publiques entre répression mortifere et réhabilitation, quand bien même cette dernière peut être conçue à la fois comme l'aboutissement de l'activisme du mouvement anti-guerre contre la drogue et comme une forme de biopolitique qui façonne, par des soins, les individus.

La seconde perspective consiste à envisager, dans une approche herméneutique critique, les potentialités de la brèche ouverte par le mouvement anti-guerre contre la drogue, les "contours émergents de ce qui peut advenir» (not-yet) (p. 13). Pour ceux qui n'en meurent pas, l'expérience de la consommation de drogues est une conversion de compétences néfastes en savoirs expérientiels qui constituent une richesse humaine, génératrice d'engagements militants, à laquelle Jarrett Zigon rend hommage tout au long de son ouvrage. Le concept d'expérience vécue, singulière, est l'un des fondements de l'éthique de construction de nouveaux mondes. Ouvrir la focale sur un problème global, considérer les possibles d'une société plus inclusive dessinent en creux un rôle assumé de l'anthropologue, comme militant concourant à un activisme fondé sur des preuves, non sans rappeler la figure sartrienne de l'intellectuel engagé.

Erwan Autès 